\title{
Blending ratio of recycled aggregate on the performance of pervious concrete
}

\author{
Yao Yanya \\ Wuxi City College of Vocational Technology, Wuxi, 214063, China \\ yaoyanya66@163.com
}

\begin{abstract}
Recycled pervious concrete as an environment-friendly and material-saving construction material can satisfy the current development demands of circular economy and environmental protection in China. But studies concerning the performance of recycled pervious concrete are not enough, which limits its application and promotion. In this study, waste prefabricated concrete beams were taken as the source of recycled aggregate and processed by crushing and screening to obtain recycled coarse aggregate. Then pervious concrete was prepared using the recycled coarse aggregate. Taking replacement rate and grain size grade as the running parameters, five groups of mix proportion were designed. Moreover the physical, mechanical and permeability performance and the interrelation were analyzed by tests. The results demonstrated that the 24-hour water absorption rate of the recycled coarse aggregate was 12 times higher than that of natural aggregate, the porosity of the pervious concrete was between $14.2 \%$ and $20.44 \%$, and the permeability coefficient was between $0.19 \mathrm{~cm}$ and $0.46 \mathrm{~cm}$ and increased with the increase of the porosity. The compressive strength of the pervious concrete increased with the increase of the replacement rate. When the replacement rate was $30 \%$, the improvement amplitude was the largest. The compressive strength was improved $35.4 \%$ after double grain grade aggregate was mixed, but the permeability performance decreased.
\end{abstract}

KEYWORDS. Recycled aggregate; Pervious concrete; Permeability; Strength.

\section{OPEN \\ ACCESS}

Citation: Yanya, Y., Blending ratio of recycled aggregate on the performance of pervious concrete, Frattura ed Integrità Strutturale, 46 (2018) 343-351.

Received: 10.06 .2018

Accepted: 10.09 .2018

Published: 12.09.2018

Copyright: (C) 2018 This is an open access article under the terms of the CC-BY 4.0, which permits unrestricted use, distribution, and reproduction in any medium, provided the original author and source are credited.

\section{INTRODUCTION}

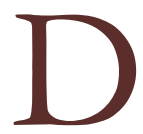

emolition wastes has exceeded 1.5 billion tons in China every year with the acceleration of urbanization development, among which, $30 \% \sim 50 \%$ is waste concrete; but the availability of the waste concrete is lower than $50 \%$ [1,2]. Therefore, recycling of waste concrete has arisen the attentions of the world. It is common to apply waste concrete in road embankment or as concrete aggregate after crashing, screening and cleaning, which can promote the sustainable development of the construction industry and has significant economic and social benefits [3,4]. Preparing 
recycled concrete with waste concrete instead of natural aggregate has been tried in the 1950s. Many scholars in China and abroad have studied the basic properties of recycled aggregate in recent years and gained substantial research achievements. Silva et al. [5] and Akbarnezhad et al. [6] found that the performance of recycled concrete was weaker than that of natural concrete. Brito et al. [7] regarded waste concrete beams with high grade as the source of recycled aggregate and found that the mixing amount of recycled aggregate had insignificant influence on the strength of concrete. Zhang et al. [8] considered that recycled aggregate could be used for preparing high-performance concrete. Though the conclusions about the performance of recycled concrete in those studies are inconsistent, preparing concrete with recycled aggregate is extensively considered as feasible. But limited by technical and social factors, its application has not been extensively promoted [9].

Pervious concrete refers to a kind of concrete with certain strength and permeability performance which is prepared by coating and binding aggregate particles with cement paste and adding or not adding fine aggregate and whose connected pores can rapidly drain away water. The porosity depends on the grain size of aggregate [10]. America has started to study and apply pervious concrete since 1970s and 1980s. China is promoting pervious concrete currently. Low impact development construction in China greatly demands pervious concrete, which means large consumption of natural aggregate. Replacing natural aggregated rocks with waste concrete totally or partially as the aggregate source of pervious concrete can save a large number of natural resources and generate significant ecological environmental benefits [11]. Studies concerning the preparation of pervious concrete based on recycled aggregate is in the early stage.

Guneyisi E et al. [12] studied the influence of different replacement rates of recycled aggregate $(25 \%, 50 \%, 75 \%$ and $100 \%$ ) on pervious concrete and evaluated the performance of pervious concrete using General Linear Model-Analysis of Variance (GLM-ANOVA). The results demonstrated that the strength of pervious concrete increased firstly and then decreased and permeability coefficient increased with the increase of the replacement rate of recycled aggregate; the permeability performance of pervious concrete increased with the increase of water cement ratio under the same replacement rate. But Zaetang et al. [13] considered that the compressive strength slightly increased when the replacement rate was lower than $60 \%$ and slightly decreased when the replacement ratio was $100 \%$. Zhu found that the compressive strength of pervious concrete was the largest when the replacement rate of recycled coarse aggregate was $30 \%$ and then decreased with the increase of the replacement rate through Gaussian curve fitting. Previous studies [14,15] considered that the basic performance of pervious concrete which was prepared using recycled aggregate could satisfy requirements; however the research methods are different, and the relationship between the replacement rate and the performance of pervious concrete has not been unified. Therefore, the performance and replacement rate of recycled aggregate and the strength and permeability performance of graded recycled pervious concrete were studied by preparing graded aggregate based on waste prefabricated concrete beams through mechanical crushing and artificial screening, which provides a theoretical basis for the the application of recycled aggregate in pervious concrete and promote the recycling of waste concrete.

\section{TEST OVERVIEW}

\section{Raw materials}

7 he raw materials included P.O 42.5 cement (Henan Mengdian Group, China) whose 28-day compressive strength was $53 \mathrm{MPa}$ and 28-day bending strength was $8.0 \mathrm{MPa}$, natural river sand (coarse sand), natural coarse aggregate (gravel with grain size between $5 \mathrm{~mm}$ and $10 \mathrm{~mm}$ ) and recycled coarse aggregate (waste road concrete blocks). Natural river sand was used as fine aggregate. The mixture of coarse sand was to ensure the strength of test specimens and improve the workability of pervious concrete and facilitate the forming of test specimens. The waste road concrete blocks were obtained by crushing with knobbling and Y132S-4 jaw crusher (Shanghai Dezhong Electric Co., Ltd., China) and screening aggregate with grain size between $5 \mathrm{~mm}$ and $10 \mathrm{~mm}$ and between 10 and $20 \mathrm{~mm}$ (in a small amount).

\section{Design of mix proportion}

Referring to relevant regulations and research achievements [16,17], water cement ratio was set as 0.30 . The replacement rate of recycled aggregate was set as $0 \%, 30 \%, 50 \%, 100 \%$ single-sized and 100\% double-sized, denoted as RC0, RC 30 , RC50, RC100 and RC100D. The double-sized recycled coarse aggregate included aggregate with grain size between $5 \mathrm{~mm}$ and $10 \mathrm{~mm}$ and between $10 \mathrm{~mm}$ and $20 \mathrm{~mm}$ (mass ratio: 6:4; with the maximum accumulation density).

The 10-min water absorption rate of recycled aggregate usually can be $90 \%$ that of aggregate in saturation state; moreover concrete mixing can be completed within $10 \mathrm{~min}$. To solve the problem of high water absorption of the recycled aggregate, added water was used in this study. The amount of added water was equal to the amount of 10-min water absorption. Influence of the water absorption of natural aggregate was not considered. 
To improve the mixing peaceability of recycled pervious concrete and ensure its strength, a small amount of coarse sand (natural river sand with fineness modulus of 3.3) was added (sand percentage: 10\%) was added (Tab. 1). The design of mix proportion is shown in Tab. 2.

\begin{tabular}{cccccccc}
\hline Aperture size $/ \mathrm{mm}$ & 9.5 & 4.75 & 2.36 & 1.18 & 0.60 & 0.30 & 0.15 \\
$\begin{array}{c}\text { Type II grading region requirement/\% } \\
\text { The first accumulative sieve residue }\end{array}$ & 0 & $0-10$ & $0-25$ & $10-50$ & $41-$ & $70-$ & $90-$ \\
$\begin{array}{c}\text { percentage/\% } \\
\begin{array}{c}\text { The second accumulative sieve residue } \\
\text { percentage/\% }\end{array}\end{array}$ & 0 & 0.5 & 11.8 & 41.9 & 65.2 & 80.4 & 92.6 \\
& 0.7 & 13.5 & 43.2 & 67.6 & 83.8 & 91.3 \\
\hline
\end{tabular}

Table 1: Natural sand grain grading.

\begin{tabular}{cccccccccc}
\hline & Replace & Sand & \multicolumn{6}{c}{ Material utilization amount per unit volume $\left(\mathrm{kg} / \mathrm{m}^{3}\right)$} \\
\cline { 6 - 10 } No. & $\begin{array}{c}\text { ment } \\
\text { rate } \%\end{array}$ & $\begin{array}{c}\text { percentag } \\
\text { e/\% }\end{array}$ & RA1 & RA2 & NA & Natural & Cement & $\begin{array}{c}\text { Water involved in } \\
\text { cement hydration }\end{array}$ & $\begin{array}{c}\text { Added } \\
\text { water }\end{array}$ \\
RC0 & 0 & 10 & 0 & 0 & 1378 & 153 & 307 & 92 & 0 \\
RC30 & 30 & 10 & 136 & 0 & 1240 & 153 & 307 & 92 & 3 \\
RC50 & 50 & 10 & 415 & 0 & 968 & 153 & 307 & 92 & 10 \\
RC100 & 100 & 10 & 1378 & 0 & 0 & 153 & 307 & 92 & 32 \\
RC100D & 100 & 10 & 826 & 550 & 0 & 153 & 307 & 92 & 28 \\
\hline
\end{tabular}

Table 2: Mix proportion of recycled pervious concrete

Note: NA: natural aggregate $(5 \sim 10 \mathrm{~mm})$; RA1: recycled coarse aggregate $(5 \sim 10 \mathrm{~mm})$; RA2: recycled coarse aggregate $(10 \sim 20 \mathrm{~mm})$

The forming and maintenance of test specimens

All the concrete was mixed using a $50 \mathrm{~L}$ blender. Firstly sand and cement were mixed evenly. Then coarse aggregate and water were added. After $3 \sim 5 \mathrm{~min}$ of mixing, the slump degree was measured, about $35 \mathrm{~mm} \sim 50 \mathrm{~mm}$. After testing of the slump degree, the concrete mixture was poured into a steel mould and tamped; the surface was smoothed. The mould was removed after 24 hours. Then it was maintained in a curing room $\left(20 \pm 2{ }^{\circ} \mathrm{C}\right.$, humidity higher than $\left.95 \%\right)$. After 28 days, all the test specimens were taken out for testing.

\section{TEST METHODS}

\section{Porosity and permeability coefficient}

he effective porosity of test specimens was calculated based on the mass variation of test specimens after being immersed in water and dried by air for $24 \mathrm{~h}$. The calculation formula is:

$$
P=\left[1-\left(\frac{\mathrm{m}_{2}-m_{1}}{\rho_{w} v}\right)\right] \times 100 \%
$$

where P stands for porosity (unit: \%), $\mathrm{m}_{1}$ stands for the mass of test specimens in water (unit: $\mathrm{g}$ ), $\mathrm{m}_{2}$ stands for the mass of test specimens after 24 hours of air drying (unit: g), $v$ stands for the volume of test specimens (unit: $\mathrm{cm}^{3}$ ), and $\varrho_{w}$ stands for the density of water at room temperature (unit: $\mathrm{g} / \mathrm{cm}^{3}$ ).

\section{Permeability coefficient}

Permeability coefficient was tested using constant water head method, and the test device is shown in Fig. 1. Pervious concrete was prepared using polyvinylchlorid pipe mould in a nominal outside diameter of $110 \mathrm{~mm} \times 150 \mathrm{~mm}$. Then the test specimens were vertically fixed at the stent in the middle of overflow gutter. Valve for water supply was opened. After the volume of water flowing from the outflow ports of the overflow gutter and porous cylinder became stable, difference of the water levels of the porous cylinder and overflow gutter $(\mathrm{H})$ was measured using a steel gauge. When the water levels were being stable for $30 \mathrm{~s}$, a second chronograph was started; at the same time, water flowing from the water outlet was 
collected using a measuring cylinder. The time $(\mathrm{t})$ and the amount of effluent water $(\mathrm{Q})$ were recorded. Each test specimen was measured thrice. The maximum and minimum values were removed from the test results, and the median was taken as the permeability coefficient of the test specimens. The calculation formula is:

$$
k_{i}=\frac{Q l}{A b t}
$$

where $K_{i}$ stands $f$ or the permeability coefficient at the i-th measurement (unit: $\mathrm{cm} / \mathrm{s}$ ), Q stands for the amount of water passing through the test specimens in t seconds (unit: $\mathrm{cm}^{3}$ ), 1 stands for the height of the test specimens (unit: $\mathrm{cm}$ ), A stands for the cross section area of the test specimens (unit: $\mathrm{cm}^{2}$ ), $\mathrm{h}$ stands for the difference of water level (unit: $\mathrm{cm}$ ), and $\mathrm{t}$ stands for the measurement time (unit: $\mathrm{s}$ ).

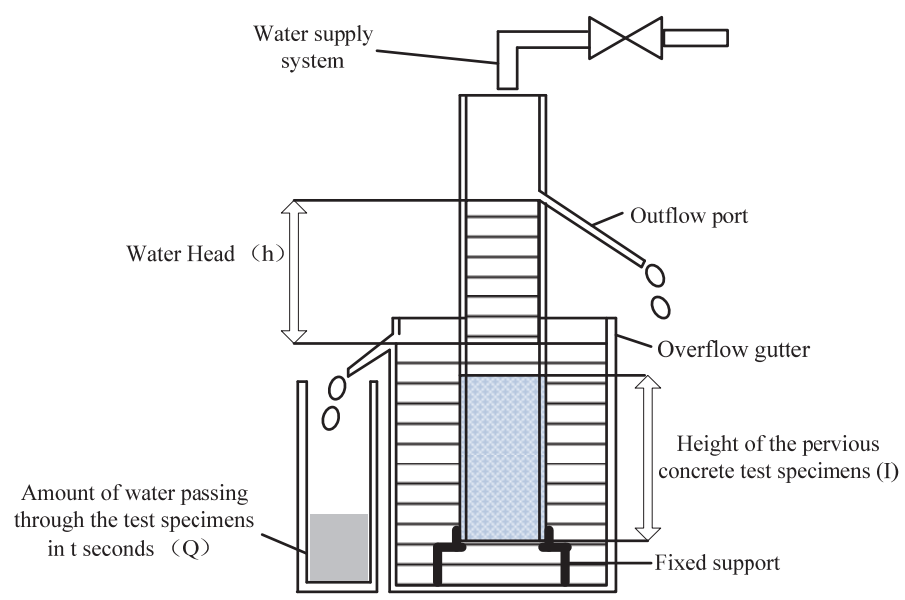

Figure 1. Test device

\section{Compressive strength and splitting tensile strength}

The compressive and splitting tensile strength of the recycled pervious concrete were tested using YAW6506 electrohydraulic servo compression testing machine according to Standard for Test Method of Mechanical Properties on Ordinary Concrete (GB /T 50081-2002).

\section{TEST RESULTS AND ANALYSIS}

\section{The analysis results of the physical properties of coarse aggregate}

$\mathrm{C}$ oarse aggregate acts as a skeleton in concrete, which determines the properties of concrete mixture and the mechanical and endurance properties after hardening. The main properties of the natural and recycled aggregate were detected using relevant regulations in this study, and the results are shown in Tab. 3.

\begin{tabular}{ccccccccc}
\hline $\begin{array}{c}\text { Physical } \\
\text { property } \\
\text { indexes }\end{array}$ & $\begin{array}{c}\text { Water } \\
\text { content/ } \\
\%\end{array}$ & $\begin{array}{c}\text { 10-min water } \\
\text { absorption/ } \%\end{array}$ & $\begin{array}{c}\text { 24-h water } \\
\text { absorption } \%\end{array}$ & $\begin{array}{c}\text { Apparent } \\
\text { density/ } \\
\left(\mathrm{kg} / \mathrm{m}^{3}\right)\end{array}$ & $\begin{array}{c}\text { Stacking } \\
\text { density/ } \\
\left(\mathrm{kg} / \mathrm{m}^{3}\right)\end{array}$ & $\begin{array}{c}\text { Porosity } \\
/ \%\end{array}$ & $\begin{array}{c}\text { Silt } \\
\text { content/ } \\
\%\end{array}$ & $\begin{array}{c}\text { Crush } \\
\text { index } / \%\end{array}$ \\
$\begin{array}{c}\text { Recycled } \\
\text { aggregate }\end{array}$ & 2.9 & 5.0 & 5.6 & 2606 & 1262 & 51.62 & 0.25 & 35.07 \\
$\begin{array}{c}\text { Natural } \\
\text { aggregate }\end{array}$ & 0.2 & 0.4 & 0.5 & 2728 & 1553 & 45.33 & 1.4 & 15.56 \\
\hline
\end{tabular}

Table 3: The physical properties of the natural aggregate and recycled aggregate.

Tab. 3 demonstrates that the water content of the recycled aggregate was 14 times that of the natural aggregate, the 24-h water absorption of the former was about 12 times that of the natural aggregate, and the 10-min water absorption of the recycled aggregate was $90 \%$ that of recycled aggregate in saturated water absorption state. It was because that the hardened mortar on the surface of the recycled aggregate was so porous that the water absorbability was strong. The 
findings were consistent with the research results of Bhutta MAR et al. [18]. Tab. 3 also demonstrated that the apparent density and stacking density of the recycled aggregate was lower than those of the natural aggregate. The study of Xu et al. [19] suggested that the apparent density and stacking density of the recycled aggregate were between $2310 \mathrm{~kg} / \mathrm{m}^{3}$ and 2620 $\mathrm{kg} / \mathrm{m}^{3}$ and between $1200 \mathrm{~kg} / \mathrm{m}^{3}$ and $1470 \mathrm{~kg} / \mathrm{m}^{3}$; and the apparent and stacking density of the recycled aggregate in this study were both within the ranges. Moreover the crushing value of the recycled aggregate was apparently larger than that of the natural aggregate, about 2 times, and the silt content of the natural aggregate was 6 times that of the recycled aggregate.

\section{The analysis results of porosity and permeability coefficient}

A previous study [20] found that the porosity of recycled pervious concrete increased with the increase of replacement rate. The relationship between replacement rate and porosity obtained in this study was in line with that rule. The porosity and permeability coefficient of the recycled pervious concrete are shown in Tab. 4. Moreover it was found that the connected porosity increased with the increase of permeability coefficient (Fig. 2), which was similar to the research results of Zaetang et al. [13]. It was because that concrete with higher porosity had suffered smaller water resistance due to the larger effective wetted area.

\begin{tabular}{rrcr}
\hline No. & Range of porosity $/ \%$ & Average porosity $/ \%$ & Average permeability coefficient $(\mathrm{cm} / \mathrm{s})$ \\
RC0 & $17.02 \sim 19.18$ & 17.8 & 0.28 \\
RC30 & $14.56 \sim 15.68$ & 14.96 & 0.26 \\
RC50 & $14.94 \sim 18.55$ & 16.18 & 0.27 \\
RC100 & $18.75 \sim 22.2$ & 20.43 & 0.47 \\
RC100D & $13.77 \sim 14.95$ & 14.20 & 0.18 \\
\hline
\end{tabular}

Table 4: Porosity and permeability coefficient.

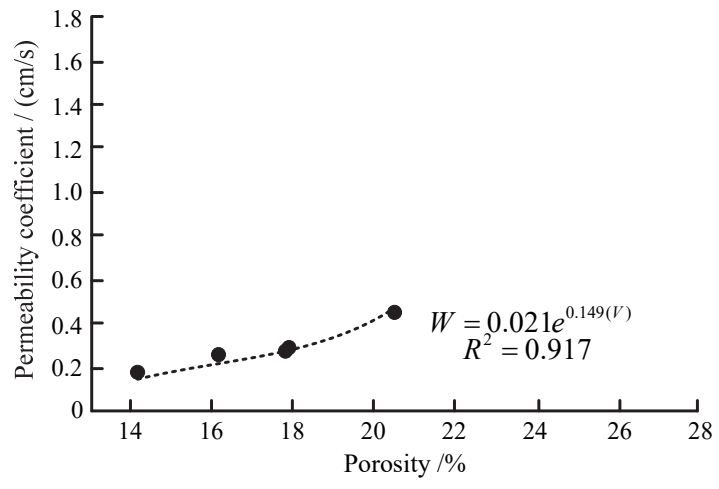

Figure 2: Porosity and permeability coefficient

The analysis of compressive and splitting tensile strength

Strength is an important parameter of pervious concrete. The application of recycled aggregate can provide enough strength for pervious concrete. The compressive strength of the recycled pervious concrete was between $3.6 \mathrm{MPa}$ and 9.07 $\mathrm{MPa}$ in this study. The variation rule of the compressive strength under different replacement rate is shown in Fig. 3 and 4.

It could be noted from Fig. 3 and 4 that the compressive strength of RC30, RC50, RC100 and RC100D were higher than $\mathrm{RC0}$, which was consistent with the current research results [21,22]. It was because that the rough surface and porous internal structure of the recycled aggregate strengthened cementation, and the water absorbed by the aggregate during mixing released to promote the development of the compressive strength. Moreover it was observed that the compressive strength gradually improved with the increase of the replacement rate; the improvement amplitude was the largest when the replacement rate was 30\%, but kept unchanged when the replacement rate was higher than $30 \%$. The compressive 
strength of RC100D was about $35.4 \%$ higher than that of RC100, indicating that grading adjustment could optimize the strength of pervious concrete. Grading adjustment could improve the stacking density and decrease the crushing value, which could improve the compressive strength and reduce dispersion.

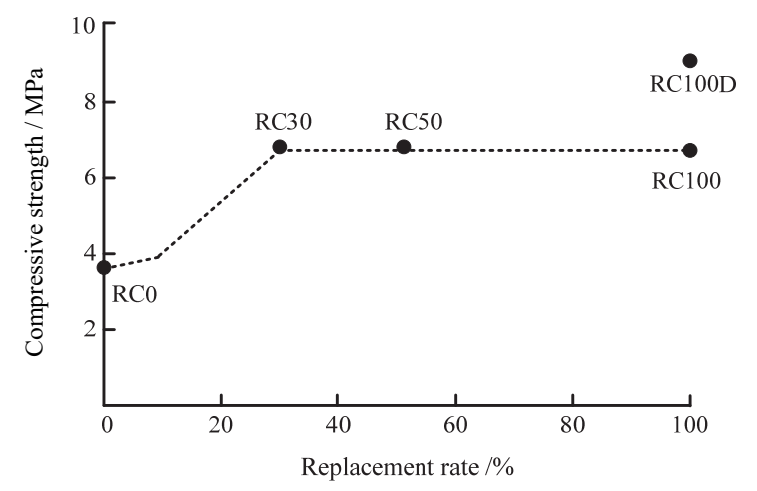

Figure 3: Compressive strength of the recycled pervious concrete.

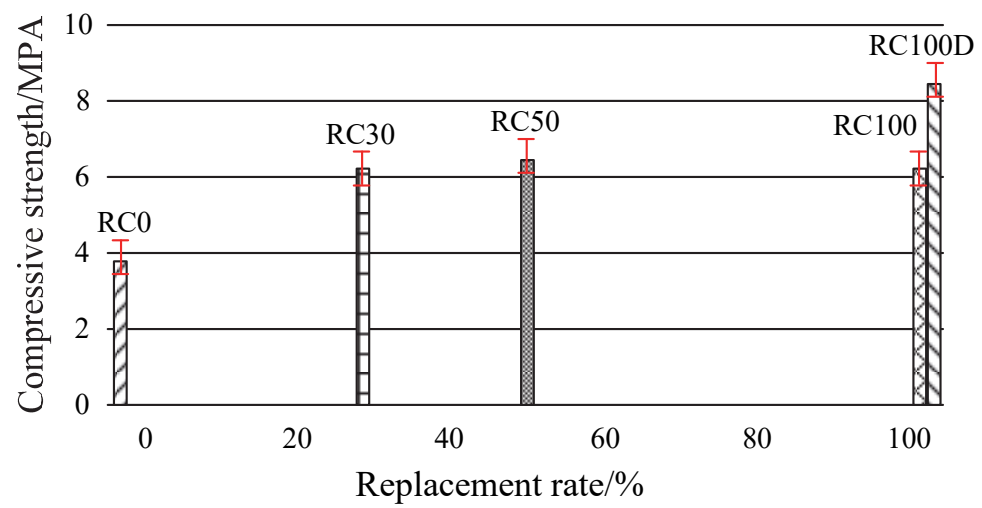

Figure 4: The diagram of the relationship between different replacement rate and compressive strength.

The compressive strength was considered in an exponential relationship with the porosity, and the compressive strength decreased with the increase of the porosity [17]. The relationship between the porosity and compressive strength found in this study was basically consistent with previous studies (Fig. 5 and 6). But RPC100 with the largest porosity, surprisingly, had the highest compressive strength. The compressive strength of porous pervious concrete is usually determined by the occlusion friction of coarse aggregate and the bounding strength between aggregate and cement mortar. The rough surface of RPC100 increased the occlusion friction between aggregate, and moreover the thickness of cement mortar between aggregate increased.

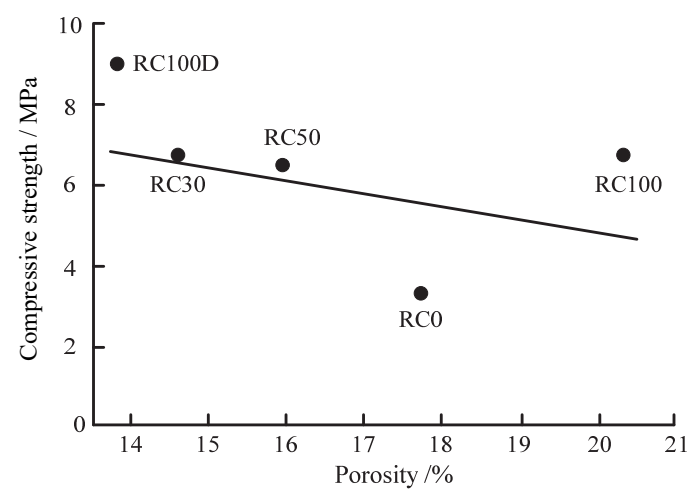

Figure 5: Porosity and compressive strength. 


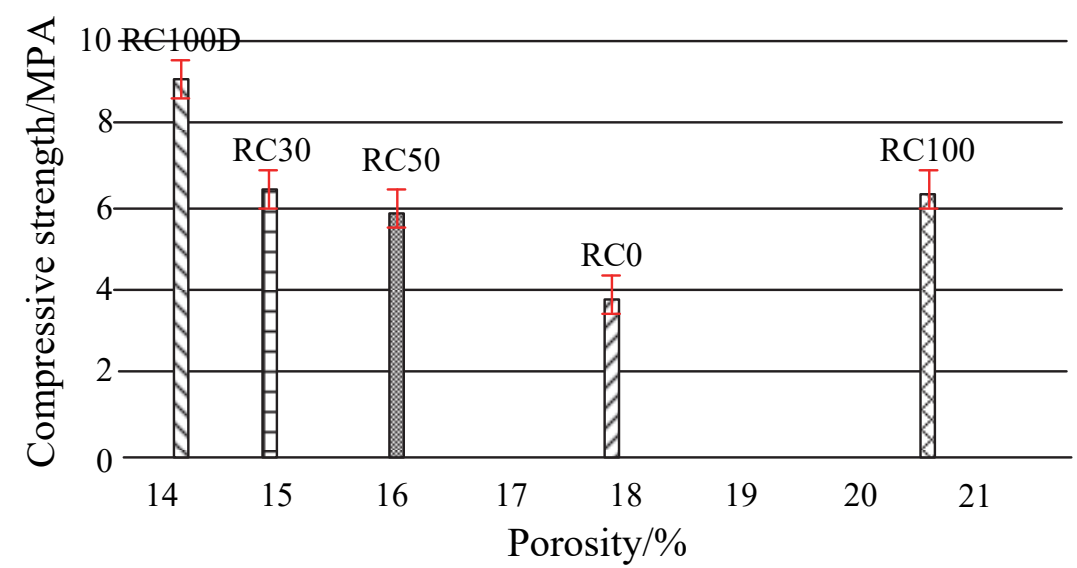

Figure 6: The diagram of the relationship between the porosity of the pervious concrete and compressive strength.

The relationship between the compressive strength and splitting tensile strength of the pervious concrete is shown in Fig.

7. The results demonstrated that the splitting tensile strength improved with the increase of the compressive strength.

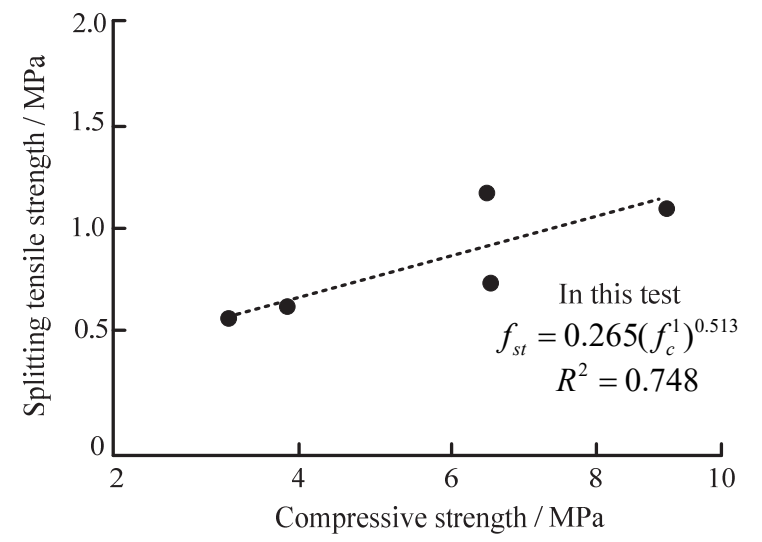

Figure 7: Compressive strength and splitting tensile strength

\section{CONCLUSIONS}

he recycled aggregate was obtained by mechanically crushing and artificially screening the waste prefabricated concrete components in this study, and moreover it was tested and analyzed to explore the effects of the mixing amount of recycled aggregate on the strength and permeability performance of pervious concrete. The main conclusions are as follows.

The water absorption of the recycled coarse aggregate was 13 times that of the natural aggregate, and its 10-min water absorption could be $90 \%$ of the recycled coarse aggregate in the saturated water absorption state. The apparent and stacking density of the recycled coarse aggregate was $95.5 \%$ and $81.2 \%$ that of the natural aggregate and the crushing value of the former was 2 times that of the latter.

Considering the high water absorption of the recycled coarse aggregate, added water whose amount was equal to the 10 min water absorption of the recycled coarse aggregate was used to avoid region with low water cement ratio. The strength and water permeability of the recycled pervious concrete satisfied the regulations. The test results were superior to the pervious concrete prepared using natural aggregate in the same proportion. Therefore it is feasible to prepare pervious concrete using recycled aggregate in the aspect of performance.

The blending ratio of the recycled coarse aggregate was in no obvious relation with the porosity changes of the pervious concrete. The porosity was the largest when the replacement rate was $100 \%$, but the permeability coefficient increased with the porosity. Moreover the addition of double grain grade aggregate improved the compressive strength of the recycled pervious concrete and decreased the porosity and water permeability. 
When the replacement rate of the recycled coarse aggregate was $30 \%$, the compressive strength of the pervious concrete was the largest, $6.71 \mathrm{MPa}$; when the replacement rate became higher than $30 \%$, the compressive strength stopped increasing. The splitting tensile strength was in a positive correlation with the compressive strength; the splitting tensile strength increased with the increase of the compressive strength. But the compressive strength was in a negative correlation with the porosity; the compressive strength decreased with the increase of the porosity.

\section{REFERENCES}

[1] Chen, Z.P., Zhou, C.H. and Chen, Y.L. (2014), Mechanical property and strain-stress constitutive relationship of recycled pebble aggregate concrete, J. Basic Sci. Engin., 22(4), pp. 763-774.

[2] Fan, J., Chen, Z.P. and Chen, Y.L. (2015), Analysis of influencing factors on compression strength and bending strength of recycled aggregate wall materials, J Basic Sci Engin, 23(6), pp. 1210-1220.

[3] Li, H. and Zhai, B.H. (2015). Policy research on promoting recycling construction waste in China, Urban Dev Res, 22(3), pp. 119-124.

[4] Sun, J.K., Ou, X.J., Ma, H.P. (2016). Research on the improvement of construction waste recovery process, Environ. Engin., 34(12), pp. 103-107.

[5] Silva, R.V., Brito, J.D. and Dhir, R.K. (2015). The influence of the use of recycled aggregates on the compressive strength of concrete:a review, Eur J Environ Civ En, 19(7), pp. 825-849.

[6] Akbarnezhad, A., Ong, K.C.G. and Zhang, M.H. (2011). Microwave-assisted beneficiation of recycled concrete aggregates, Constr. Build. Mater., 25(8), pp. 3469-3479.

[7] Brito, J.D., Ferreira, J. and Pacheco, J. (2016). Structural, material, mechanical and durability properties and behaviour of recycled aggregates concrete, J. Build. Engin., 6, pp. 1-16.

[8] Zhang, Y.M., Qin, H.G. and Sun, W. (2002). Preliminary study on mix proportion design of recycled concrete, China Concrete Cement Prod, (1), pp. 7-9.

[9] Andreu, G. and Miren, E. (2014). Experimental analysis of properties of high performance recycled aggregate concrete, Constr Build Mater, 52(2), pp. 227-235.

[10] Zhang, S.T., Jia, X.Y. and Song, Z. (2016). Mix proportion design of sand free recycled pervious concrete, China Concrete Cement Prod, (12), pp. 6-12.

[11] Chen, S.L., Yang, Q. and Liu, Q.C. (2017). Experimental on the strength and permeability of recycled aggregate pervious concrete, Trans Chin So Agricult Eng., 33(15), pp. 141-146.

[12] Guneyisi, E., Gesoglu, M. and Kareem, Q. (2016). Effect of different substitution of natural aggregate by recycled aggregate on performance characteristics of pervious concrete, Mater. Struct., 49(1), pp. 521-536.

[13] Zaetang, Y., Sata, V. and Wongsa, A. (2016). Properties of pervious concrete containing recycled concrete block aggregate and recycled concrete aggregate, Constr. Build. Mater., 111, pp. 15-21.

[14] Barnhouse, P.W. and Srubar, W.V. (2016). Material characterization and hydraulic conductivity modeling of macroporous recycled-aggregate pervious concrete, Constr. Build. Mater., 110(02), pp. 89-97.

[15] Yang, X.G., Hao, Y.C. and Xue, Y. (2012). Study on the basic properties of recycled aggregates, Concrete, (2), pp. 6668.

[16] Zhang, X.C., Yin, J. and Chi, Y. (2010). Summary of performance for pervious concrete, Concrete, 12, pp. 47-50.

[17] Sriravindrarajah, R., Wang, N.D.H. and Lai, J.W.E. (2012). Mix design for pervious recycled aggregate concrete, Int J Concrete Struct Mater, 6(4), pp. 239-246.

[18] Bhutta, M.A.R., Hasanah, N. and Farhayu, N. (2013). Properties of porous concrete from waste crushed concrete (recycled aggregate), Constr. Build. Mater., 47, pp. 1243-1248.

[19] Xu, Y.Z. and Shi, J.G. (2006). Analyses and evaluation of the behaviour of recycled aggregate and recycled concrete. Concrete, (7), pp. 41-46.

[20] Omary, S., Ghorbel, E. and Wardeh, G. (2016). Relationships between recycled concrete aggregates characteristics and recycled aggregates concretes properties, Constr. Build Mater., 108, pp. 163-174.

[21] Cai, H.Y., Zhang, M. and Dang, L.B. (2012). Experimental study on compressive strength of recycled aggregate concrete with different replacement ratios, Appl Mechan Mater., (6), pp. 1277-1280.

[22] Yao, Y.F., Jin, B.H. and Zhang, H.G. (2016). Influence of replacement rate of recycled coarse aggregate on mechanical properties of recycled concrete, J Guangxi Univ (Nat Sci Ed), 41(4), pp. 1187-1193. 


\section{APPENDIX}

RC0 a pervious concrete sample which is composed of single-sized aggregate and whose replacement rate of recycled aggregate is $0 \%$

RC30 a pervious concrete sample which is composed of single-sized aggregate and whose replacement rate of recycled aggregate is $30 \%$

RC50 a pervious concrete sample which is composed of single-sized aggregate and whose replacement rate of recycled aggregate is $50 \%$

RC100 a pervious concrete sample which is composed of single-sized aggregate and whose replacement rate of recycled aggregate is $100 \%$

RC100D a pervious concrete sample which is composed of double-sized aggregate and whose replacement rate of recycled aggregate is $100 \%$

Porosity the ratio of the volume of open pores inside the pervious concrete to the volume of the pervious concrete

Permeability a parameter representing the permeability performance of concrete, which refers to the volume of coefficient water passing through pervious concrete per unit area in unit time. 